\title{
Hybrid Multi-Agents and Case Based Reasoning for Aiding Green Practice in Institutions of Higher Learning
}

\author{
Bokolo ANTHONY JNR., Mazlina ABDUL MAJID, Awanis ROMLI
}

\begin{abstract}
Sustainability is a concern that has been raised in many domains especially in institutions of higher learning such as universities. Hence, universities are implementing Green practices to promote sustainability. Similarly Green practice implementation in universities for attaining sustainability has been the priority for most universities across the world, mainly in ensuring the effectiveness and efficiency of Information Technology (IT) related service. Over the years, a few approaches have been developed to facilitate Green practice in institutions of higher learning, however these approaches are not autonomous and do not provide adequate information on Green implementation initiatives. Moreover, institutions of higher learning utilize manual checklist assessment questionnaire to evaluate their current Green practice. Therefore, this study proposes a system model that integrates hybrid multi-agent and Case Based Reasoning (CBR). The CBR technique facilitates Green implementation by providing information on how institution of higher learning can adopt Green practices initiative, whereas software agents autonomously assess the current Green practice initiative implemented in institutions of higher learning. Findings from this paper show how the hybrid multi-agent and CBR aid universities implement Green practice for sustainability attainment in institutions of higher learning.
\end{abstract}

Keywords: Hybrid Multi-Agents; Case Based Reasoning; Sustainability; Green Practice Implementation; Institutions of Higher Learning

\section{INTRODUCTION}

The world is currently faced with addressing environmental challenge in relation to climate changes, loss of the natural environment and utilization of natural resources [1]. With global warming evolving as a major concern, sustainable development is rapidly changing from a simple issue into an important agenda [2]. Therefore, there is need for Institutions of Higher Learning (IHL) to implement Green practice initiatives in supporting sustainability for waste decrease, energy efficiency, water utilization reduction, healthy campus surroundings as well as clean indoor air. These initiatives can bring about improved quality of life for all, better economic vitality and a reduced environmental footprint [3].

Sustainability is a concern that has been discussed in many global conferences particularly in the educational domain. The idea of sustainability has gained international attention since its inception in the Brundtland tagged "Our Common Future" during the United Nations Conference on Environment and Development in the year 1987 [4]. Green practice for sustainability attainment in institutions of higher learning is a growing field of consideration and practice, yet attaining ecological friendly practices in university operations is still considered an issue [2]. Hence Green practice in institutions of higher learning is a dynamic interaction between humans and the natural environment in transforming sustainability into practice [5]. Although it is mainly challenging to attain sustainability in institution of higher learning, due to the number of students, academic staffs, non-academic staffs, practitioners and university activities. Nevertheless, there is need to promote Green practices to decreases energy and water utilization while achieving negligible $\mathrm{CO}_{2}$ emissions and reduced waste generation [5].

Therefore, this study explores on two techniques from Artificial Intelligence (AI) that can be used to aid university Green practice implementation. Moreover, findings from previous research showed that institutions have reduced their technical support costs with up to $33 \%$ by deploying techniques from artificial intelligence [6]. Thus, this study focuses on integrating hybrid multi-agent and Case Based Reasoning (CBR) to aid Green practice in institutions of higher learning. Correspondingly, agents are computational entities that can be characterized through their capacities in areas such as autonomy, reactivity, pro-activity, social abilities, reasoning, learning and mobility [6]. These capabilities make multi-agent very appropriate for deploying intelligent environments.

Furthermore, agents can act as an interface between the user and the rest of the elements in a system [7]. Moreover agents can incorporate advanced AI procedures to aid assessment [8]. Agents act as software that brings about a certain result or is empowered to act for another by perceiving its environment through sensors and effectors. The general aim of agents is to accomplish certain goals or objectives they are designed to achieve [9]. In addition multi-agents is an interconnected network of individual agents interacting and working together to achieve common goals in performing distributed tasks concurrently. One of the main aims of a multi-agent is to find solutions to complex system problems and to handle tasks that are beyond the ability of a single agent [10].

Similarly CBR is a technique that solves new problems based on the solutions of similar past problems by retrieving similar cases from a case base, university users in institution of higher learning can reuse, revise solutions from similar cases and obtain the final confirmed solution for the new problem [10]. In CBR, new solutions dealing with a current situational circumstance are generated by retrieving the most similar cases from the case base and adapting the case in the present contexts. CBR working procedure is composed of four steps: retrieve, reuse, revise and retain. CBR is suitable in dealing with real world, open-ended, complex problems (such as Green practice implementation) [7]. Besides CBR is one of the evolving paradigms for developing intelligent systems for providing information. It shows significant potential for enhancing the efficiency of unstructured and complex decision-making [11].

Therefore, this paper proposes a system model that integrates hybrid multi-agents and CBR. The CBR technique facilitates Green practice by providing 
information on how institutions of higher learning can implement Green practices, whereas hybrid multi-agents autonomously assess the current Green practice implemented in IHL. The structure of this paper is organized as follows: section 2 presents the literature review. Section 3 is the methodology; section 4 is applicability of CBR in the proposed system model. Section 5 is the discussion and implication. The final section is the conclusion, limitation and future directions.

\section{LITERATURE REVIEW \\ 2.1 Overview of Software Agent}

An agent is a field of artificial intelligence (AI), a sub domain of autonomous computing. The concept of agent technology was first invented by John McCarthy in the year 1950, and the term was invented by Oliver Selfridge G. some years later. According to Jnr et al. [7] agent is a soft robot residing and doing its assigned task inside the computer's world. Agents are considered as a determined software entity committed to a definite purpose [11]. Over the years there have been varying definitions for agent; this is due to the fact that the different characteristics of an agent can vary in its importance in different fields or domains. Hence agents are generally described as computational entities, software components or computer systems that are capable of performing autonomous actions on behalf of their users [10].

Due to their independent and social abilities, agents have been used in a wide variety of complex applications. Agents perform actions according to the information they perceive from their environment [12]. With the use of sensors, agents can sense and gather information from their environment. They use this information to perform certain actions on their environment [6]. The general aim of agents is to execute the goals or objectives they are designed to achieve. Hybrid multi-agent is an interconnected network of agents capable of interacting with one another. The agents work together to achieve common goals and are capable of performing distributed tasks concurrently [8].

Therefore, this study integrates hybrid multi-agents to assess benchmark and rate institution of higher learning Green practices. Moreover hybrid multi-agents is an appropriate technique that can be applied to aid university Green practice since agents can make decisions based on coordination of other agents in a collaborative environment as seen in Fig. 1. Besides each individual agent executes its own decisions to implement specific services and then coordinates with other agents and humans such as university users as seen in Fig. 1 to accomplish their aim.

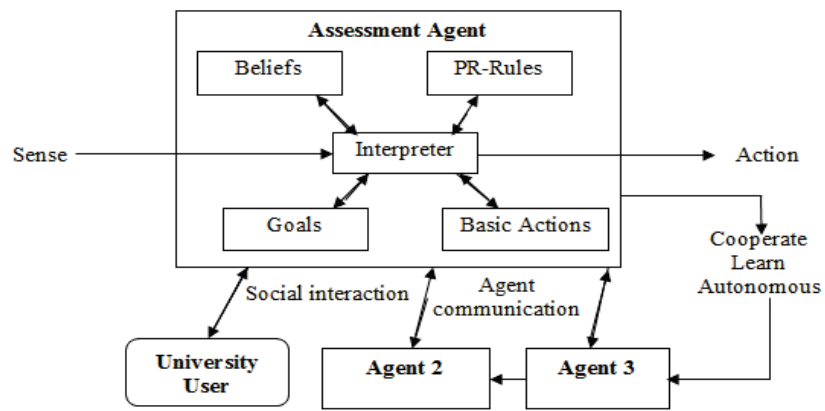

Figure 1 Overview of a multi-agent deployment adopted from [7]
Fig. 1 shows an example of an agent (assessment agent) that can sense and act to its environment. It can also interact and communicate with other agents and humans (university users). The assessment agent collaborates with other agents in evaluating, benchmarking and rating institution of higher learning current Green practice. The algorithm of the agent presented in Fig. 1is given as:

AGENT "assessment_agent"

BASIC_ACTIONS:

$\{$ benchmark(Green practice) $\}$ rate() $\{$ NOT

sustainable(Green practice), benchmark(Green

practice) $\}$,

\{benchmark(Green practice) $\}$ rate() $\{$ rate(Green

practice), sustainable(Green practice) $\}$

BELIEF

\{benchmark(Green practice)\}

GOAL:

evaluate()

RULE:

evaluate ()$\leftarrow$ benchmark(Green practice) $\mid$ rate( $)$; score(),

evaluate ()$\leftarrow \operatorname{rate}($ Green practice $) \mid$ rate () ; score () .

Based on the above algorithm the assessment agent is deployed based on its assigned goal, which is triggered by its predefined rules (PR-rules) which results in the agents' actions (evaluating, benchmarking and rating universities current Green practice).

\subsection{Background of Case Based Reasoning}

The origins of Case Based Reasoning (CBR) can be traced back to late 1980s. CBR technique was first proposed by Professor Roger in the year 1982 in the domain of artificial intelligence. CBR is one of the evolving paradigms for developing intelligent systems [10]. CBR shows significant potential for enhancing the efficiency of unstructured and complex decision-making. CBR was first deployed in data structures called Memory Organization Packets (MOPs) which constituted several generalized knowledge repositories or case base [13]. The case based stores large set of previous cases with their solutions to be utilized by other users [11]. CBR comprises four procedures: retrieve, reuse, revise and retain as seen in Fig. 2.

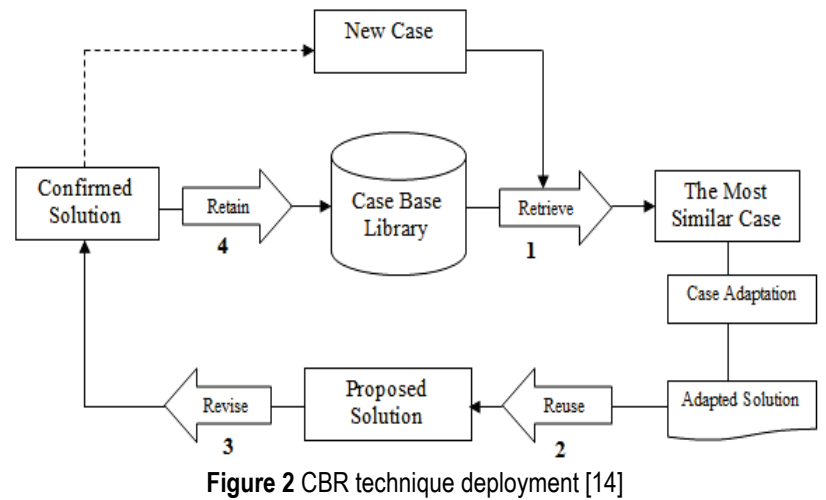

Fig. 2 shows a typical CBR technique deployment cycle. The retrieval phase in the CBR technique retrieves similar cases from the case base. Indexing schemes and 
similarity metrics are used for this purpose. Indexing enables the efficient retrieval of relevant cases from the case base, thus limiting the search time. Similarity metrics assess the relevance of the retrieved cases to the new case. A simple approach to similarity assessment is the nearest neighbour matching [14]. One or more retrieved cases, deemed most relevant to the new case, are used for dealing with it. In the reuse phase, a solution for the new case is created based on the retrieved most relevant case(s). The revise phase validates the correctness of the proposed solution, perhaps with the control of end user.

Finally, the retain phase decides whether the knowledge learned from the solution of the new case is important enough to be incorporated into the system. Quite often the solution contained in the retrieved case( $\mathrm{s}$ ) is adapted to meet the requirements of the new case. Usual adaptation methods are substitution, transformation and derivational replay [14]. For the adaptation task, domain knowledge, usually in the form of rules, is employed. CBR integrates knowledge during its operation to enhance its reasoning capabilities. This is a major advantage of CBR, since typical intelligent knowledge base systems only employ static data representations during data retrieval operations [10].

\subsection{Related Works}

Several researches have contributed to support institutions of higher learning adopt Green practice in universities, a few of these studies are reviewed briefly in this section to explore on the problem solved and the issues that have not been addressed. Tab. 1 shows prior studies carried out to facilitate Green practice implementation in institutions of higher learning towards sustainability attainment.

Table 1 Prior research on Green practice for sustianability attainment in instituions of higher learning

\begin{tabular}{|c|c|c|c|}
\hline Authors & Contribution & Problem Solved & Methodology Applied \\
\hline $\begin{array}{l}\text { Ahmad et al. } \\
{[15]}\end{array}$ & $\begin{array}{l}\text { Examined Malaysian universities students' } \\
\text { perception towards Green computing. }\end{array}$ & $\begin{array}{l}\text { Provided the need for a university to implement Green } \\
\text { initiatives to increase campus awareness. }\end{array}$ & $\begin{array}{l}\text { Survey data from } 224 \\
\text { respondents. }\end{array}$ \\
\hline $\begin{array}{l}\text { Ismail et al. } \\
{[16]}\end{array}$ & $\begin{array}{l}\text { Explored the factors that influence employees to } \\
\text { adopt telecommuting in their universities. }\end{array}$ & $\begin{array}{l}\text { Presented an understanding on the current standing of } \\
\text { university employees' perception to telecommuting. }\end{array}$ & $\begin{array}{l}\text { Survey data from } 300 \\
\text { usable datasets. }\end{array}$ \\
\hline Isa [17] & $\begin{array}{l}\text { Investigated the level of awareness among } \\
\text { university academic employees in relation to the } \\
\text { practice of a sustainable campus. }\end{array}$ & $\begin{array}{l}\text { Suggested curriculum, research, operations, services } \\
\text { and outreaches, buildings and physical environment as } \\
\text { vital areas for sustainable campus. }\end{array}$ & $\begin{array}{l}\text { Questionnaire from } 186 \\
\text { academic staffs. }\end{array}$ \\
\hline $\begin{array}{l}\text { Bakhshi et al. } \\
\qquad[18]\end{array}$ & $\begin{array}{l}\text { Studied Green campus practice towards promoting } \\
\text { Green open space in university campus. }\end{array}$ & $\begin{array}{l}\text { Evaluates quality of open space for learning } \\
\text { environments and identifies features that promote its } \\
\text { quality as meaningful to student. }\end{array}$ & $\begin{array}{l}\text { Mixed mode case study } \\
\text { and questionnaire from } \\
100 \text { participants. }\end{array}$ \\
\hline Reza [19] & $\begin{array}{l}\text { Described existing programs and research activities } \\
\text { of public and private higher educational institutions } \\
\text { in Malaysia towards sustainability. }\end{array}$ & $\begin{array}{l}\text { Provided recommendations to improve and } \\
\text { develop sustianability programs in higher education } \\
\text { systems in Malaysia. }\end{array}$ & $\begin{array}{l}\text { Secondary data (review } \\
\text { of the literature) }\end{array}$ \\
\hline $\begin{array}{l}\text { Azlin et al. } \\
\quad[20]\end{array}$ & $\begin{array}{l}\text { Explored the perception of employees based on } \\
\text { their understanding of the concept of a sustainable } \\
\text { practice towards preserving the environment.. }\end{array}$ & $\begin{array}{l}\text { Identified how to increase awareness among the } \\
\text { campus community to be more efficient in preserving } \\
\text { the environment for the future. }\end{array}$ & $\begin{array}{l}\text { Questionnaire from } 100 \\
\text { respondents. }\end{array}$ \\
\hline Zen et al. [4] & $\begin{array}{l}\text { Described how to implement waste minimization } \\
\text { governance for university sustainability. }\end{array}$ & $\begin{array}{l}\text { Investigated how to minimize dry waste and provide } \\
\text { strategies for paper saving and recycling. }\end{array}$ & $\begin{array}{l}\text { Case study document } \\
\text { review. }\end{array}$ \\
\hline $\begin{array}{c}\text { Ismail et al. } \\
{[21]}\end{array}$ & $\begin{array}{l}\text { Proposed how university campus can achieve an } \\
\text { Energy Management System (EMS). }\end{array}$ & $\begin{array}{l}\text { Identified how EMS can be deployed to achieve five } \\
\text { per cent electricity consumption decrease yearly. }\end{array}$ & $\begin{array}{l}\text { Case study document } \\
\text { review. }\end{array}$ \\
\hline $\begin{array}{l}\text { Ayog et al. } \\
\text { [22] }\end{array}$ & $\begin{array}{l}\text { Deployed rain water harvesting in support of eco- } \\
\text { friendly campus initiative as Green infrastructure. }\end{array}$ & $\begin{array}{l}\text { Proposed rainwater harvesting to reduce water bill for } \\
\text { sustainable water management. }\end{array}$ & Case study. \\
\hline Nifa et al. [5] & $\begin{array}{l}\text { Designed a framework to enabling sustainable } \\
\text { design in planning for campus development. }\end{array}$ & $\begin{array}{l}\text { Stipulates how maintanace departments can improve } \\
\text { and implement sustainable practice in universities. }\end{array}$ & Case study by interview. \\
\hline
\end{tabular}

Tab. 1 summarized prior studies carried out to support Green practice in universities towards achieving sustainability, although each of the researchers contributed towards sustainability none of the studies suggested an approach to facilitate Green practice by providing information on how universities can implement Green practices and also evaluate their current Green practice implemented in institution of higher learning.

\subsection{Existing Works on Application of Multi-Agents and CBR}

Over the years a few studies have integrated multiagents and CBR in their area of research, and among these studies eight studies are reviewed briefly in this section. One of the selected studies was presented by Leite and Girardi [8] where the authors developed hybrid software agent architecture integrated with CBR for reactive learning behaviour for continuous interactions of the agent within its environment. Shen et al. [10] proposed methodological tools and steps for integrating CBR and multi-agent system to achieve an ontological application towards proving decision support in clinical domain. De Loor et al. [6] applied CBR and agents adapted for more precisely real-time interactive retrieval mechanisms based on an adequate case base structure associated with a dedicated recall algorithm, to enhance retrieval efficiency. Linghu and Chen [9] designed an intelligent multi-agent method for flood disaster forecasting based on CBR. Vargas et al. [11] employed agents and CBR to implement a web-designed system to support monitor software process as part of a strategy to encourage software development industry.

Zouhair et al. [23] developed intelligent tutoring systems based on multi-agent and CBR to deploy learning and provide an adapted follow-up of students when they interact with the system. Floyd and Esfandiari [24] suggested a CBR and agent based framework that supports agents to learn by observation in deployed environments. When learning by observation, agents perceive end users executing a task and learning to implement the same task based on previous recognized observations.

Haghighatjoo et al. [12] deployed strategic agents and CBR for selecting an efficient seller and successful 
strategy, respectively when competition is involved, the agents negotiate untill an agreement is reched. The eight studies reviewed successfully applied multi-agents and CBR techniques in their research. Thus this study is motivated to apply hybrid multi-agents and CBR to facilitate Green practice in institution of higher learning towards attaining sustainability.

\section{METHODOLOGY}

Hybrid multi-agents and CBR techniques are applied to facilitate Green practice in institutions of higher learning. According to Shen et al. [10] recent studies have confirmed that a hybrid method can combine the advantages of multi-agents and CBR techniques, as such overcomes the limitations of both techniques. The hybrid multi-agents and CBR system model are developed as shown in Fig. 3 to emulate intelligent reasoning of human beings, where the case base can be seen as the brain in the proposed system model for storing Green best practice to support institutions of higher learning Green practice for sustainability attainment.

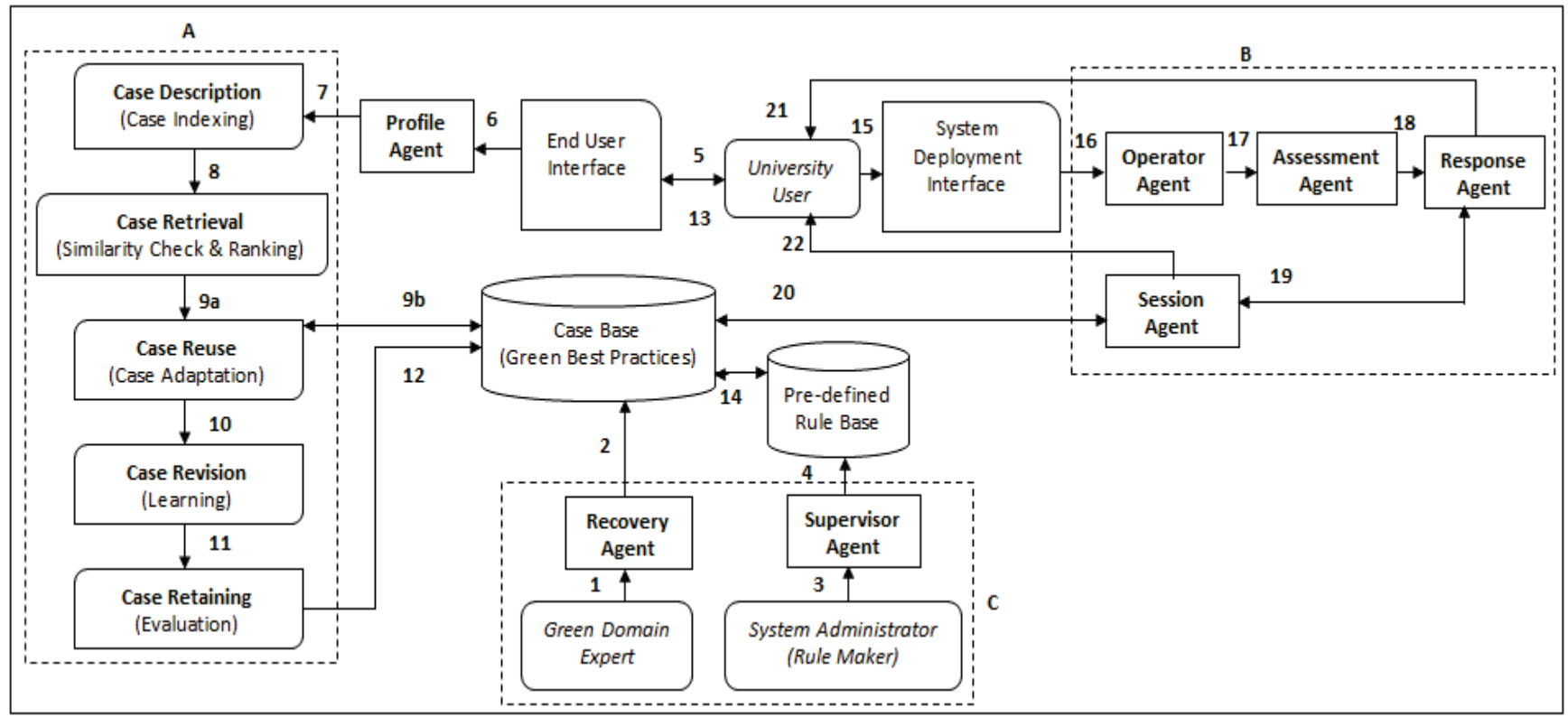

Figure 3 Proposed multi-agents and case based reasoning system model

Fig. 3 depicts the hybrid multi-agents and CBR system model developed to support institutions of higher learning implement Green practice. The A portion shows how CBR is applied to facilitate Green implementation by providing information on how university users can deploy environmental friendly practices in their university. The B portion shows how hybrid multi-agents collaborate and communicate to assess the current Green practice implemented in institutions of higher learning by university users. Similarly, the $\mathrm{C}$ portion shows how hybrid multi-agents and CBR aid university users and domain experts.

1 - The Green domain experts who have experience on Green practice add new information on how universities can improve their current Green practice. They also add Green assessment questions and respective answers.

2 - Recovery agent saves all data into the case base as Green best practices.

3 - System administrator who is the rule maker set predefines procedures to provide Green solution to university users when the case base does not provide any answer or when it is empty.

4 - Supervisor agent adds all set rules to the predefined rule base.

5 - University users search for information on Green practice implementation through end user interface which comprises the university users' web browser.
6 - Profile agent executes the search query using Structured Query Language (SQL) executed by the university user.

7 - The case description is called using case indexing to search for similar Green cases in the case base.

8 - This leads to case retrieval where the Green cases in the case base are checked based on weighting of Green case parameters after which the cases are ranked based on cases that are more similar to the search keyword.

9a, 9b -The Green case can be reused by university user in deploying Green practices. In addition the solution can be adapted by the university user to be compatible with the current situation after which the case is saved to the case base.

10 - The adaptation of an existing case will lead to the revision of the existing case in the case base. This will assist CBR to learn of the new or adapted solution.

11 - Once a selected Green case has been adapted by the university user the case is evaluated and revised to be retained in the case base.

12 - Next, after case retaining and evaluation, the Green case is saved in the case base.

13 - The retrieved case is display to the university user through the end user interface.

14 - If no similar Green case(s) is retrieved from the case base, CBR retrieves a suitable Green case from the pre-defined rule base established on the procedures set by the rule maker, which is usually the system administrator. 
15 - University user proceeds to evaluate his/her current Green practices through the system deployment interface.

16 - The system deployment interface calls the operator agent who prompts the university user to authenticate to create a session before commencing the Green practice assessment.

17 - Once the university user is logged in the operator agents present specified Green practice evaluation question and respective answers to the university, after which the assessment agent calculates, benchmarks and rates the university user Green practice based on the Green assessment questions and valid answers provided.

18 - Response agent collects the assessment sessions data and sends the data to the session agent.

19 - Session agent saves the assessment session into the Green assessment table in the case base.

20 - The university users' assessment sessions data are saved into the case base, so that the information can be retrieved by the university user to view his/her assessment benchmark and rating grade.

21 - The response agent retrieves and displays the assessment grade of the university user to verify if the university Green practices are sustainable or not sustainable.

22 - The session agent retrieves and displays Green implementation suggestions to university user based on invalid answers provided by the university user during the assessment session.

\section{APPLICABILITY OF CBR IN THE PROPOSED SYSTEM MODEL}

This section describes the applicability of CBR in the proposed system model shown in Fig. 3 in providing suggestions on how IHL can implement Green practice.

\subsection{Case Description}

Currently IHL deploy manual based assessment by utilizing questionnaire checklist assessment tools. Such methods usually are not fully automated and also do not provide features such as assessment report. Hence to execute proper case retrieval, it is mandatory for new cases to be effectively described. The past Green practice implementation knowledge is stored in the case base as shown in Eq. (1).

$$
C\left(C=\left\{\text { cncp }=1,2,3, \ldots, \text { total }_{c}\right\}\right),
$$

where $c n$ is the $n^{\text {th }}$ prior Green case, $c p$ is the case parameters and total is the total sum of past Green cases. Each Green case consists of five parameters which include case number, case index, case category, problem description and recommended solution (see Tab. 2).

\subsubsection{Case Indexing}

In the proposed system model CBR checks if an old case is applicable to a new problem by comparing the similarities between parameters of the problem and data in the case base. If the new problem is applicably similar to a previous solution description, the case(s) is selected. The case solution part provides suggestion or practical steps that can be implemented by university user. Further a case number is assigned to every case. The case number is always a numerical value assigned to all cases and can range from 1 to $n^{\text {th }}$ value, after which is the case index which specifies the essential content of a case. The case is retrieved from the case based by the university user based on searched keyword(s), where the keyword parameter is very beneficial for operational case retrieval.

Table 2 Case structure and content [2]

\begin{tabular}{|c|l|l|}
\hline $\begin{array}{c}\text { Parameter } \\
\text { No }\end{array}$ & \multicolumn{1}{|c|}{ Case Parameter } & \multicolumn{1}{c|}{ Parameter Value } \\
\hline 1 & Case number & Integer, from 1 to $n$. \\
\hline 2 & Case index & Vector, \{keyword1, keyword $n\}$. \\
\hline 3 & Case category & Binary value, private or public. \\
\hline 4 & Problem description & $\begin{array}{l}\text { Text, including problem domain } \\
\text { and problem definition. }\end{array}$ \\
\hline 5 & $\begin{array}{l}\text { Recommended } \\
\text { solution }\end{array}$ & $\begin{array}{l}\text { Text, including possible solution } \\
\text { and recommendation steps. }\end{array}$ \\
\hline
\end{tabular}

$C i=\sum_{1=1}^{i} j P i j=(P i 1, P i 2, P i 3, \ldots \ldots \ldots$, Pin $)$

In relation to case indexing, in Eq. (2) $C$ represents a case and each parameter $P i j$ represents each case index parameter.

\subsection{Case Retrieval}

CBR usually depends on this step, as such once the university user searches for a case the CBR procedure recovers similar Green cases from the case base. The phase aims to discover the best analogous case by comparing similarity between the new searched case and existing case. Comparison metrics such as Euclidean distance, city block distance, geometric similarity metrics, probabilistic similarity measure, Mahalanobis distance or nearest neighbour (NN) are used by $\mathrm{CBR}$ to execute case comparison [25]. However, this study applies The Nearest Neighbour (NN) algorithm for measuring the similarity of the problem case and solution cases as shown in Eq. (3).

$\operatorname{sim}(N C, R C)=\sum_{1=1}^{n} w_{i} * \operatorname{sim} \frac{\left(N C_{i}, R C_{i}\right)}{\sum_{1=1}^{n} w_{i}}$,

where $N C$ is new Green case, $R C$ is retrieved Green case, $N C_{i}$ and $R C_{i}$ are the parameter $i$ of the new Green case $N C$ and $R C$ correspondingly, $w_{i}$ is the weight of case parameter $i$, and $\operatorname{sim}\left(N C_{i}, R C_{i}\right)$ is the similarity value of case parameter $i$. In addition, the value of $\operatorname{sim}\left(N C_{i}, R C_{i}\right)$ is computed as shown in Eq. (4).

$\operatorname{sim}\left(N C_{i}, R C_{i}\right)=1 \frac{\left|N C_{i}-R C_{i}\right|}{\left|N C_{i}\right|+\left|R C_{i}\right|}$.

\subsubsection{Similarity Check and Ranking}

The similarity check detects how similar are a case parameters searched to existing Green case in the case base. According to Jihani et al. [25] there are three procedures utilized for this step and they include inductive, 
nearest neighbour and knowledge guided. Knowledge guided is not usually used because it involves a lot of data to be available to be effective. Inductive method uses a large number of cases to create an induction tree, but often criticized for not deploying efficient case retrieval. Conversely, the NN algorithm is commonly used to identify similarity between two or more cases when the retrieval parameters are not well defined or when the cases available are few. Nevertheless, one of the limitations of the NN algorithm is that it is challenging to implement case parameter weights which are important in achieving accurate retrieval of cases [25]. As suggested by Fang and Won [26] this study integrates NN algorithm for deploying case similarity check based on the keyword searched by the university user, after which the cases are ranked and displayed as presented in Fig. 4.

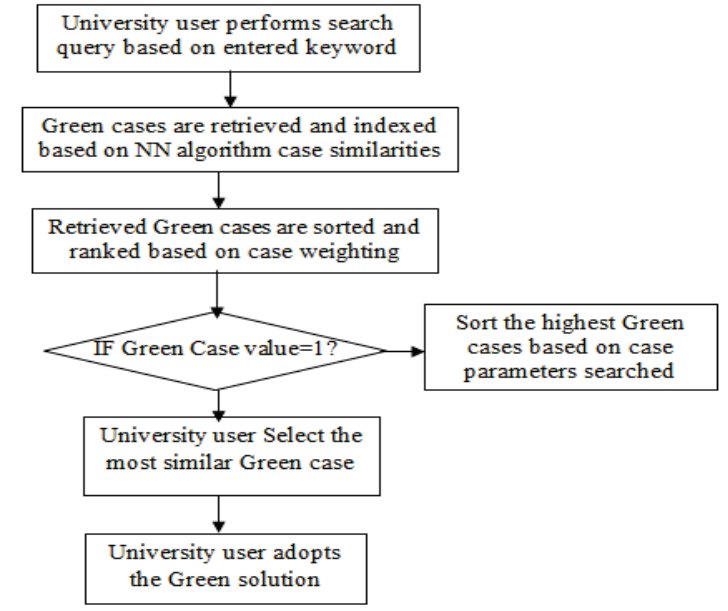

Figure 4 Flow chart of case retrieval (similarity check and case ranking)

Fig. 4 shows the flow chart that highlights the method executed in deploying similarity check and case ranking. University user searches for case solution on Green practice implementation based on case parameter weight value. The similarity check and ranking of the case is based on the weight value assigned to each case parameter as shown in Eq.(5).

$D_{p s}=\sum_{1=k}^{n} W_{k}\left|X_{p k}-C B_{s k}\right|$

where $D_{p s}$ means distance between the problem $p^{\text {th }}$ that is searched by the university user and $s^{\text {th }}$ solution cases with reference to the case parameters. $W$ represents the weight assigned to the case parameters. $X$ is the selected case chosen by the university user, while $C B$ is the case base.

\subsection{Case Reuse}

This phase involves the university user selecting the most suitable solutions from the retrieved ranked Green cases. Once the most similar case is chosen by the university user, it will be directly reused as a suggested solution. The similarity between a new problem and an existing Green case retrieved to be reused by the university user is calculated as follows:

$\operatorname{sim}(S Q, C B)=\sum_{1=1}^{n} w_{i} * \operatorname{sim}\left(P_{i}, S_{i}\right)$ where $S Q$ is the search query executed by the university user, $C B$ is the case base and $w$ indicates the weight assigned to case parameters respectively. $P_{i}$ is the problem case and $S_{i}$ is the solution selected by the university user.

\subsubsection{Case Adaptation}

In the CBR cycle the retrieved case may not be directly applicable mostly due to change of technology or requirements. In this condition the selected solutions presented are not usually applied by the user and are adapted before they can be applied to solve the current problem [27]. This phase usually uses algorithms such as weighted average, majority voting, arithmetic average, etc. Still, it is challenging to execute the case adaptation process as most of such CBR based systems exclude this stage. In addition case adaptation involves changing and adjusting old case parameter values to help university user implement the retrieved case recommendation. Consequently the knowledge of the university user needs to be elicited in the phase. As mentioned by Fang and Wong [27] the knowledge of the user is needed in understanding how to apply the selected case to suit his/her own preference, CBR deploys Eq. (7) to allocate the adapted case an initial value $A C(a)$ :

$$
A C(a)=n \sum_{1=1}^{n} W_{a c}=1 \frac{[\operatorname{sim}(a, a c) * A C(a c)]}{n},
$$

where $A C(a c)$ is the value of the adapted case $a c, n$ is the number of selected cases adapted and $\operatorname{sim}(a, a c)$ is the solution similarity between the initial case $c$ and adapted case $a c$.

\subsection{Case Revision}

This phase encompasses modifying existing case solution based on the adapted case by verifying the adapted solution for the new problem. In addition in this phase CBR learns about revised Green cases executed by university users. Moreover case revision usually entails replacing previous solution for a particular problem with adapted solution. Similarly after the new case solution has been verified based on real world applicability and correctness, the validated solution is saved as a new learnt case and stored into the case base for future reuse. This phase is a distinctive feature of CBR technique which differentiates it from other intelligent learning techniques. The revision of a retrieved case is updated by the feedback provided by the university user. Eq. (8) describes how a selected solution $s i$ is revised based on the survival value $P V(s i)$ of the Green case.

$P V($ new $)(s i)=P V($ new $)($ si $)+\Delta P V($ si $)$,

where

$\Delta P V(s i)=(\operatorname{Sat}(s i)-0.45) * L$

As seen in Eq. (9) Sat(si) represents the value of approval degree of solution selected by the university user 
$s i$, and $L$ represents the CBR learning rate, set to 0.1 as suggested by Yang [27] for gradually modifying Sat(si).

\subsubsection{Learning}

The learning is an experience activity designed for case evaluation and retaining procedures, thus if a suggested Green case is applied to solve a problem and is later specified by the university user that the recovered case is effective, CBR learns about this. Consequently the recommended case chosen by most university users will have higher significance when other university users search for similar problems in future. Certainly, if a case was chosen to address a target problem by a university user, the ranking score of the particular case would result to +1 . The higher score denotes the greater priority in case ranking. Consequently, this procedure can constantly enhance case based learning and ranking result, hence based on Eq. (8) CBR identifies the survival (importance) value of a selected case solution as $\triangle P V(s i)$ presented in Eq. (9) is redefined as Eq. (10).

$$
\Delta P V(s i)=(\operatorname{Sat}(1)-0.45) * \operatorname{sim}(c, a) * 1
$$

Likewise, Tab. 3 shows that 0.45 is the moderate satisfaction value for any solution case selected by the university user. Thus, CBR learning is derived based on the representation values in Tab. 3 .

Table 3 Satisfaction degrees and their representation $[25]$

\begin{tabular}{|l|c|}
\hline \multicolumn{1}{|c|}{ Satisfaction degree } & Representative value \\
\hline Highly satisfied & 0.80 \\
\hline Satisfied & 0.65 \\
\hline Moderate & 0.45 \\
\hline Unsatisfied & 0.25 \\
\hline Highly unsatisfied & 0.10 \\
\hline
\end{tabular}

\subsection{Case Retaining}

This phase involves storing resulting new cases for future reference in the case base as Green best practice, after the solution has been effectively deployed to address present problem. The case to be retained in the case based is saved based on input satisfaction value added by university users. Thus as stated previously Tab. 3 shows the satisfaction degrees of university users which are based on the feedback provided by university users. Although since the selected case solution $s i$ was adapted as $A C(a)$ in Eq. (7). CBR does not retain the previous retrieved case shown in Eq. (3) instead Eq. (11) is used for case retaining. Where $s i_{\text {new }}$ is the assign of a survival value to the adapted case solution and $P V_{\text {ave }}$ is the averaged survival value of the case in case base.

$$
P V\left(s i_{\text {new }}\right)=P V_{\text {ave }} * S_{a t}\left(s i_{\text {new }}\right),
$$

where

$$
P V_{\text {ave }}=n \sum_{1=1}^{n} \frac{P V(s i)}{n} \text {. }
$$

\subsubsection{Evaluation}

In this phase CBR retrieves and displays ranked list of most similar cases the university user receives and also estimates if the case solutions suggested are able to resolve the existing problems, if the retrieved answers are able to address the present issues, the retrieved cases are perceived as effective cases. If not the university user can search for more suitable Green case solutions after the revision phase. To evaluate which case is to be saved in the case base (previous solution case or case adapted by university user) CBR take into account the similarity of the previous solution case against the case adapted by university user. As shown in Eq. (13).

$$
\operatorname{sim}(\operatorname{si}, a c)=\frac{|S s i \cup S a c|}{|S s i \cap S a c|},
$$

where $a c$ is the case adapted by university user, $s i$ is the selected case solution, $\mathrm{Sac}$ is the solution part of the adapted case $a c$ and $S s i$ is the solution part of the select case solution $s i$ and $\operatorname{sim}(s i, a c)$ measures the extent to which the selected case contributes to solving the new problem in relation to the adapted form of the solution.

\subsection{Case Base (Green Best Practices)}

This comprises all the Green cases that have been successfully implemented previously. The case base can be referred to as Green best practices. The case base also contains Green assessment questions and answers used to assess university users' current Green practice. Thus, a case base $C B$ containing $n$ number of cases may be expressed as given in Eq. (14).

$$
C B=\sum_{1}^{n} C n=(C 1, C 2, C 3, \ldots \ldots, C n) .
$$

\subsection{Pre-defined Rule Base}

This phase provides Green practice suggestion to university user if the case base does not have a direct solution for new problems. Thus Green solutions can be generated to university users' bases on existing pre-defined rules added in the rule base by system administrator or rule experts as shown in Eq. (15).

$$
S i=\sum_{1}^{n} k W_{i k} * \frac{W_{k}}{\sqrt{\sum_{1}^{n} k\left(W_{i k}\right) 2 \sum_{1}^{n} k\left(W_{k}\right) 2}},
$$

where $W_{k}$ is the weight of the $n^{\text {th }}$ term in the pre-defined rule case base. However this equation is executed only if the retrieved Green cases from the case base are not able to solve the target problem searched by the university user in implementing Green practice.

\section{DISCUSSION AND IMPLICATION OF STUDY}

In computer information systems, an agent is software that acts or brings about a certain result; it is one who is empowered to act for another. Moreover agent can be 
defined as a software entity, which is autonomous to accomplish its design objectives through the axiom of communication and coordination with other agents. According to Vargas et al. [11] multi-agent involves individual software agents that collaborate and interact to solve problems. Similarly in CBR new problems are solved based on similar past problems. This is deployed by retrieving similar cases from a case base. Hence, users can reuse and revise solutions from similar cases and obtain the final confirmed solution for the new problem.

In this study CRR and hybrid multi-agents were infused to provide feature of the flexibility, adaptability and autonomy for knowledge sharing towards Green practice implementation in Institutions of Higher Learning (IHL). Hybrid multi-agents are integrated with CBR to support university users gain access to knowledge by retrieving past solved cases, adapting these cases to enhance current Green practice thus assisting the decision making of university users towards attaining sustainability. CBR uses case similarity procedures to identify and measure cases that are similar in terms of the case parameter weights [7]. Case parameter similarities measures in CBR involve the use of non-numeric values in calculating the parameter similarity between two strings. CBR facilitates university users to implement Green practice strategies without having to produce solutions from scratch each time they want to implement any Green initiative.

Findings from this study show how hybrid multi-agent integrated with CBR facilitates university users in institutions of higher learning in implementing Green practices. Furthermore hybrid multi-agents and CBR system model were proposed to assess university users' current Green practice. Moreover the proposed system model provides suggestions to university users on how they can improve their current Green practice toward attaining sustainability in their institution.

In addition finding from this study shows the application of software agents and CBR in the reuses of the past successful Green practice implementation knowledge to address a new problem encountered by university users. More importantly, CBR provides best practice knowledge on how university user modifies or adapts retrieved case for Green implementation. Findings also show how the deployment model utilizes operator agent, assessment agent, response agent and session agent in evaluating university users Green practices implemented.

Likewise practical implication of the study is ascribed to the proposed hybrid multi-agents and CBR system model which provides Green practice knowledge as recommendations for institutions of higher learning. Similarly hybrid multi-agents and CBR system model certify that suggested Green knowledge of domain experts can be retrieved and utilized by other university users, staffs and students in institutions of higher learning for reducing energy usage, decreasing $\mathrm{CO}_{2}$ emission, lessening cost incurred, minimizing natural resource consumption and implementing ecologically friendly waste management towards caring for the natural environment towards achieving sustainability.

For managerial implication the hybrid multi-agents and CBR model assist IHL achieve ecological sustainability and attain energy saving and carbon footprint decrease, reduce natural resources wasting and address environmental pollution related issues. In addition the system model is deployed based on less expertise to be applied in universities. Moreover the deployment model also contains few mathematical equations, thus is easy to be implemented in institutions of higher learning.

\section{CONCLUSION, LIMITATIONS AND FUTURE DIRECTIONS}

Artificial intelligence (AI) offers a number of approaches and techniques with prospective benefits if deployed properly. Hybrid multi-agent and CBR paradigm is one of AI techniques. Hybrid multi-agent and CBR possess the potential for implementing decision support systems that can facilitate Green practice in universities. At the moment universities adopt manual based checklist assessment questionnaires to evaluate their current Green practice. They also infer to paper based manuals to guide in implementing Green practice. Thus this study was motivated to propose a hybrid multi-agents and CBR system model to provide information on how Green practice can be implemented in Institutions of Higher Learning (IHL). The model deploys hybrids multi-agents to assess and grade university's current Green practice if the practice is sustainable or unattainable.

However the system model possesses a few limitations, one of which is due to the fact that CBR requires adequate number of cases to efficiently act and learn. Also CBR cannot differentiate case parameters with ambiguous data (where ambiguous refers to a word with different meaning). Another limitation of the model is that the hybrid multi-agent assessment questions and answers are based on data added by domain experts, thus if no domain experts are available there will be inadequate Green assessment questions and answers. Thus there is need for the model to be able to suggest Green assessment questions and similar answers autonomously.

Future direction will involve addressing case ambiguity by integrating Analytic Hierarchy Process (AHP). Furthermore there is a need to collect real data from universities that presently implement Green practices to enhance the robustness of CBR results in providing rigorous retrieval solution. In addition AHP will aid Green assessment question and answer generation when no domain experts are available to add Green practice questions and answers. Finally a web based tool will be implemented based on the proposed system model for aiding institutions of higher learning in implementing Green practices for achieving sustainability.

\section{REFERENCES}

[1] Plavac, B., Filipan, V., Sutlović, I., \& Svetičič, J. (2017). Sustainable waste management with mechanical biological treatment and energy utilization. Tehnički vjesnik, 24(4), 1283-1289.

[2] Jr, B. A., Majid, M. A., \& Romli, A. (2017). A Green information technology governance framework for ecoenvironmental risk mitigation. Progress in Industrial Ecology, an International Journal, 11(1), 30-48 https://doi.org/10.1504/PIE.2017.086154

[3] Mat, S. O. H. I. F., Sopian, K., Mokhtar, M., Ali, B., Hashim, H. S., Rashid, A. K. A., \& Zain, M. F. M. (2011). Managing 
Sustainability in Universiti Kebangsaan Malaysia, Environmental Problems and Development, 33-38.

[4] Zen, I. S., Subramaniam, D., Sulaiman, H., Saleh, A. L., Omar, W., Salim, M. R. (2016). Institutionalize waste minimization governance towards campus sustainability: A case study of Green Office initiatives in Universiti Teknologi Malaysia. Journal of Cleaner Production, 135(1), 14071422. https://doi.org/10.1016/j.jclepro.2016.07.053

[5] Nifa, F. A. A., Nawi, M. N. M., Nadzri, W., Osman, S. A. R. (2015). Towards Development of Sustainable Design in Malaysian University Campus: A Preliminary Framework for Universiti Utara Malaysia. Jurnal Teknologi, 77(5), 4349

[6] De Loor, P., Bénard, R., \& Chevaillier, P. (2011). Real-time retrieval for case-based reasoning in interactive multiagentbased simulations. Expert Systems with Applications, 38(5), 5145-5153. https://doi.org/10.1016/j.eswa.2010.10.048

[7] Jnr, B. A., Majid, M. A., \& Romli, A. (2017). Application of Intelligent Agents and Case Based Reasoning Techniques for Green Software Development. Technics Technologies Education Management, 12(1), 30-43.

[8] Leite, A. \& Girardi, R. (2014). A Case-Based Reasoning Architecture of a Hybrid Software Agent. Proceedings of the 2014 IEEE/WIC/ACM International Joint Conferences on Web Intelligence (WI) and Intelligent Agent Technologies, 79-86. https://doi.org/10.1109/WI-IAT.2014.153

[9] Linghu, B. \& Chen, F. (2014). An intelligent multi-agent approach for flood disaster forecasting utilizing case based reasoning. Fifth International Conference on Intelligent Systems Design and Engineering Applications, 182-185. https://doi.org/10.1109/ISDEA.2014.48

[10] Shen, Y., Colloc, J., Jacquet-Andrieu, A., \& Lei, K. (2015). Emerging medical informatics with case-based reasoning for aiding clinical decision in multi-agent system. Journal of biomedical informatics, 56(1), 307-317. https://doi.org/10.1016/j.jbi.2015.06.012

[11] Vargas, E. C., Oktaba, H., Guardati, S., \& Laureano, A. L. (2007). Agents, case-based reasoning and their relation to the Mexican software process model (moprosoft). $31^{\text {st }}$ Annual International Computer Software and Applications Conference, 326-334. https://doi.org/10.1109/COMPSAC.2007.54

[12] Haghighatjoo, M., Masoumi, B., \& Meybodi, M. R. (2014). Strategic agents for multi-resource negotiation using learning automata and case-based reasoning. $4^{\text {th }}$ International eConference on Computer and Knowledge Engineering, 35-41. https://doi.org/10.1109/ICCKE.2014.6993342

[13] Cvjetković, M., Djordjević, D., \& Ćoćkalo, D. (2017). Influence of knowledge and quality on business performance of companies in Serbia. Tehnički vjesnik, 24(3), 847-853.

[14] Anthony, B., Majid, M. A., \& Romli, A. (2016). A case based reasoning decision support model for Green ITIS diffusion in collaborative enterprise. IEEE Conference on Open Systems, 1-6. https://doi.org/10.1109/ICOS.2016.7881979

[15] Ahmad, T. B. T., Bello, A., \& Nordin, M. S. (2014). Exploring Malaysian university students' awareness of green computing. GSTF Journal on Education (JEd), 1(2), 92-102.

[16] Ismail, F. D., Hamsa, A. A. K., \& Mohamed, M. Z. (2016). Factors Influencing the Stated Preference of University Employees towards Telecommuting in International Islamic University Malaysia. Transportation Research Procedia, 17(1), 478-487. https://doi.org/10.1016/j.trpro.2016.11.097

[17] Isa, N. K. M. (2017). Sustainable campus and academic staffs awareness and behaviour in Malaysia's institutions of higher learning: A case study of UPSI. Geografia-Malaysian Journal of Society and Space, 12(6), 89-99.
[18] Bakhshi, M., Othman, N., \& Wahab, M. H. B. (2015). Green Campus in Promoting Green Open Spaces in University Technology Malaysia Kuala Lumpur Campus. International Joint conference SENVAR-iNTA-AVAN, 90-103.

[19] Reza, M. I. H. (2016). Sustainability in Higher Education: Perspectives of Malaysian Higher Education System. SAGE Open, 6(3), 1-9. https://doi.org/10.1177/2158244016665890

[20] Azlin, A. Z. B., Er, A. C., Abd Rahman, N. B., \& Alam, A. S. A. (2016). Consumers' roles and practices towards sustainable UKM campus. International Journal of Advanced and Applied Sciences, 3(2), 30-34.

[21] Ismail, M. A., Al-Obaidi, K. M., \& Sulaiman, R. (2016). Energy Efficiency Policy for Existing Typical Campus Buildings in the University of Malaya. Planning Malaysia Journal, 14(5), 129-144. https://doi.org/10.21837/pmjournal.v14.15.198

[22] Ayog, J. L., Bolong, N., \& Makinda, J. (2015). Feasibility Study of Rainwater Harvesting in Universiti Malaysia Sabah's Residential Colleges in Support of the Eco-Campus Initiative. $2^{\text {nd }}$ Regional Conference on Campus Sustainability: Capacity Building in Enhancing Campus Sustainability / Kota Kinabalu, Malaysia, 206-216.

[23] Zouhair, A., Amami, B., Boukachour, H., Person, P., \& Bertelle, C. (2012). Intelligent tutoring systems founded on the multi-agent incremental dynamic case based reasoning. 2012 Colloquium in Information Science and Technology, 74-79. https://doi.org/10.1109/CIST.2012.6388066

[24] Floyd, M. W. \& Esfandiari, B. (2011). A case-based reasoning framework for developing agents using learning by observation. $23^{\text {rd }}$ International Conference on Tools with Artificial Intelligence, 531-538. https://doi.org/10.1109/ICTAI.2011.86

[25] Jahani, A., Azmi Murad, M. A., Bin Sulaiman, M. N., \& Selamat, M. H. (2015). An agent-based supplier selection framework: Fuzzy case-based reasoning perspective. Strategic Outsourcing: An International Journal, 8(2/3), 180-205. https://doi.org/10.1108/SO-01-2015-0003

[26] Fang, F. \& Wong, T. N. (2010). Applying hybrid case-based reasoning in agent-based negotiations for supply chain management. Expert Systems with Applications, 37(12), 8322-8332. https://doi.org/10.1016/j.eswa.2010.05.052

[27] Yang, S. Y. (2013). Developing an energy-saving and casebased reasoning information agent with web service and ontology techniques. Expert Systems with Applications, 40(9), 3351-3369. https://doi.org/10.1016/j.eswa.2012.12.044

\section{Contact information:}

Bokolo ANTHONY JNR., PhD, Research Fellow

Faculty of Computer Systems \& Software Engineering (FSKKP), Universiti Malaysia Pahang, Lebuhraya Tun Razak, 26300 Gambang, Kuantan, Pahang, Malaysia bkanjr@gmail.com

Mazlina ABDUL MAJID, PhD, Associate Professor Faculty of Computer Systems \& Software Engineering (FSKKP), Universiti Malaysia Pahang, Lebuhraya Tun Razak, 26300 Gambang, Kuantan, Pahang, Malaysia mazlina@ump.edu.my

\section{Awanis ROMLI, PhD, Senior Lecturer}

Faculty of Computer Systems \& Software Engineering (FSKKP), Universiti Malaysia Pahang, Lebuhraya Tun Razak 26300 Gambang, Kuantan, Pahang, Malaysia awanis@ump.edu.my 